\title{
Pedestrian Walkable Power Generation and Harvesting
}

\author{
A. Aranganathan ${ }^{1}$, T. Gomathi ${ }^{2}$, S. Poonguzhali ${ }^{3}$, Megalan Leo ${ }^{4}$ and V. Vedanarayanan ${ }^{5}$ \\ 1, 2,3,4,5 Sathyabama Institute of Science and Technology, Chennai, 600119 Tamil Nadu, India
}

\section{ABSTRACT}

The age of electrical energy through non-regular way when individuals stroll on the floor there certain powers apply these powers, for the most part, squanders when the individual people walk. The aim of this research work is to convert the energy from mechanical footsteps to electrical energy by using Piezo transducers and micro DC generator that is called "Walkable advance system which generates power. The energy form floor is used to interpret the mechanical energy into electrical power. The proposed advanced power generation system that uses the combination of Piezo-electric sensors and micro DC generator to generate the power through footsteps or can obtain a force which is a source of energy and it can be renewable one while walking or passing through the certain arrangement like stepping foot on Piezo tiles. KEY WORDS: U DC PIEZOELECTRIC SENSOR, MICRO GENERATOR, ELECTRICAL ENERGY, MECHANICAL ENERGY,
FOOTSTEPS.

\section{INTRODUCTION}

Presently a day's energy is one of the most significant issues far and wide. Particularly in Bangladesh vitality emergency is a major issue. Sustainable power sources can be an extraordinary medium to unwind this vitality emergency issue in nations like Bangladesh. As we as a whole realize regular assets will complete sooner or later. That is the reason scientists are attempting to present substitute vitality sources from nature. That must be green and not hurtful for the earth. Power collecting is characterized as catching moment measures of vitality from at least one of the encompassing vitality sources. Individuals have just started to utilize power reaping innovation inside the type of windmill, geothermal and sun oriented vitality power source. Sustainable power source collecting plants produce kW or MW level force; it is called large scale power gathering innovation.

\section{ARTICLE INFORMATION}

*Corresponding Author: arangaece@gmail.com

Received 9th Oct 2020 Accepted after revision 27th Dec 2020

Print ISSN: 0974-6455 Online ISSN: 2321-4007 CODEN: BBRCBA

Thomson Reuters ISI Web of Science Clarivate Analytics USA and Crossref Indexed Journal

\section{Clarivate
Analytics}

NAAS Journal Score 2020 (4.31)

A Society of Science and Nature Publication,

Bhopal India 2020. All rights reserved.

Online Contents Available at: http//www.bbrc.in/

Doi: $h t t p: / / d x$.doi.org/10.21786/bbrc/13.13/47
Additionally, miniaturized scale power likewise can deliver from those characteristic sources that are called smaller scale power reaping. Small scale power collecting innovation depends on mechanical vibration, mechanical anxiety, warm power from heater, radiators and grinding sources, daylight or light, physical body, concoction or organic sources, which may create milli-W or miniaturized scale $\mathrm{W}$ level force. Miniaturized scale power supply needs are expanding incredibly with time as our innovation is moving to a smaller scale and nano manufacture levels. Our conversation on this depends on creating miniaturized scale power from vibration and weight utilizing piezoelectric material and DC engine Kumar, H. and Ramesh, G.P (2019). Piezoelectric impact is the impact of explicit materials to create an electric charge in reaction to applied mechanical pressure the transformation of energy that depleted and squandered while strolling or running. This energy is changed over into electrical energy.

1.2. Literature Survey: Power has become a lifesaver for the human populace. The requirement for power is expanding step by step. Some innovation needs a gigantic electrical capacity to perform different tasks. As we know electrical power may have obtained from sources like water, wind, etc. Piezoelectric transducer has the following merits: 
- High electromechanical conversion efficiency.

- Machinability improves.

- Different material compositions provide broad range of characteristics $\mid$

- Improved stability.

The flux cutting may also proposed as by the Faraday's law of induction by coils. Right now, gear instrument with magnet joined to the pole is utilized to produce AC voltage.

Suprati Sen et al. (2018) analyzed the Footstep power age utilizing piezoelectric material. This contains 14 piezoelectric sensors which are associated with sequential to create the power. Since the force age is from sequentially associated sensors the force produced is low however it is progressively adaptable because of its sequential association regardless of whether any of the association from the piezoelectric plate gets harmed. The piezoelectric plate is coupled with the spring and by the help of sheet course of action is finished by this method; force will be created by the power applied by the spring to vibrate piezoelectric plates. Credit is given to the person on foot for the vitality which they created. The yield power is relied upon to be 3 to $4 \mathrm{~V}$ in the model.

Shiraz Afzal et al. (2018) demonstrated Power age by strides which endeavor to show how a lot of energy can without much of a stretch be produced by utilizing a straightforward course of action. The force which is being squandered superfluously is being changed over into productive one which helps in the decrease of energy emergency and assumes a significant job in financial advancement just as a sound environment. Right now fixation is fundamentally on the ideal utilization of piezoelectric precious stones and movies in high vibration framework with proficient course of action to get higher product yield. Also, the enhancement procedure is planned so that the produced yield is adequate for the versatile charging. Strides are utilized for the creation of electrical force. Electrical vitality created by stride is all that could be needed.

Ali Muhan et al. (2018) focused on the Piezoelectric Actuator power age in which age of intensity is finished by utilizing various piezoelectric sensors. More force can be created by utilizing a more noteworthy number of sensors and can be executed on railroad stations. Substations, film theatres which are packed spots. Piezoelectric sensors are associated with a $3 \mathrm{~mm}$ LED which shines on the activation of piezoelectric plates indicating that the force is created. The created power is put away in battery-powered battery and these batteries force can be utilized to charge cell phones, workstations and helping of bulbs.

Kenji Uchino et al. (2018) proposed Power age utilizing strides in which rack and pinion game plan is introduced. The rack and pinion, spring course of action is fixed at the slanted advance. The spring gave to restore the slanted advance in the same situation by discharging the heap. The pinion shaft is associated with the supporter by end bearing. The bigger sprocket likewise combined with the pinion shaft, so it is running at a similar speed of cylinder. The greater sprocket is coupled to the little cycle sprocket with the help of a chain. These wires are related to LEDs, to show the yield power. Here the chain drive segment turns simply a single way (game-plan is made for that). In the underlying advance, the steps are directly connected with the Rack and pinion approach.

Asif Ali et al. (2018) suggested Energy age utilizing strides which contains pinion and rack game plan. The stride course of action is utilized to create the electric force. Right now mechanical vitality is changed over into electrical energy. This segment is developed by elastic or other material which is put inside the surface regions. This segment is primarily put in the crowded regions. This stride game plan is appended with the spring segment. Here the chain drive instrument turns just a single way. The rack and pinion action which is followed in association with the strides is the first step involved in the action. There are a lot more expansions that can be made to this task. Generators of more burden limit can be utilized to get more force.

Adhithan A et al. (2018) proposed Power age utilizing Staircase game plan. The spring stairs is used to push up whenever an individual is climbing the stairs or coming down from the stairs. The energy is utilized to work the force flywheel through a single direction ratchet gadget utilizing a drive. The energy stored in flywheel is used for nonstop pivot of the generator pulley and belt drive framework. It comprises of three stages that means the staircase box unit. All stages are coupled to the enormous apparatus, which thus is coupled to the little rigging through the chain drive. The little apparatus thus is coupled to the wrench wheel, permitting just the unidirectional revolution of the fastener wheel of the sleeve shaft. Moreover, every two huge rigging wheels are independently coupled to a similar single shaft through the different chain system. At the point when an individual is strolling on the individual stage, while this specific pair of apparatuses pivots the wrench haggle the fundamental shaft turns as of now. Along these lines, the whole of the absolute aggregation.

1.3. Objectives: In this footstep power generation project, the objective is to convert footsteps, walking and running energy into electricity. It is used to generate electricity by walking in footsteps or any pressure expelled on the arrangement. The need for electrical energy is increasing day by day. But power generations from conventional resources are not enough for a complete demand of electricity. Therefore, many researchers are working on nonconventional ways of electrical power generation. Footstep power generation system is additionally a non-conventional electricity production system. It converts energy of footsteps into electricity by using a piezoelectric sensor and dc motor. This power generation system can become very fashionable among crowded countries like China, India. It is often implemented on roads, bus stations, and many crowded places. 


\section{METHODOLOGY}

The fundamental working rule of our task depends on the piezoelectric sensor and DC motor. To execute this, we alter the wooden plates above and underneath the sensors and moveable springs. Non-regular energy utilizing stride is changing over mechanical energy into the electrical energy. The stride board comprises of a piezoelectric sensor and DC generator which are associated with equal. When the weight is applied to the arrangement, the sensor and dc generator will change over mechanical energy into electrical energy. This electrical energy will store in the $12 \mathrm{v}$ battery-powered battery associated with the inverter. We are utilizing a regular battery charging unit likewise for offering supply to the hardware. This inverter is utilized to change over the 12 Volt D.C to the 230 Volt A.C. This 230 Volt A.C voltage is utilized to actuate the heaps. By utilizing we can charge mobiles or can be used to lightening street lights.

1.5. Block Diagram Description: The system that we proposed consists of the Arduino controller, Piezoelectric sensor, DC generator, voltage sensor, charge controller, rectifier, booster, LCD, battery, USB hub.

Figure 1.1: Block Diagram of Proposed system

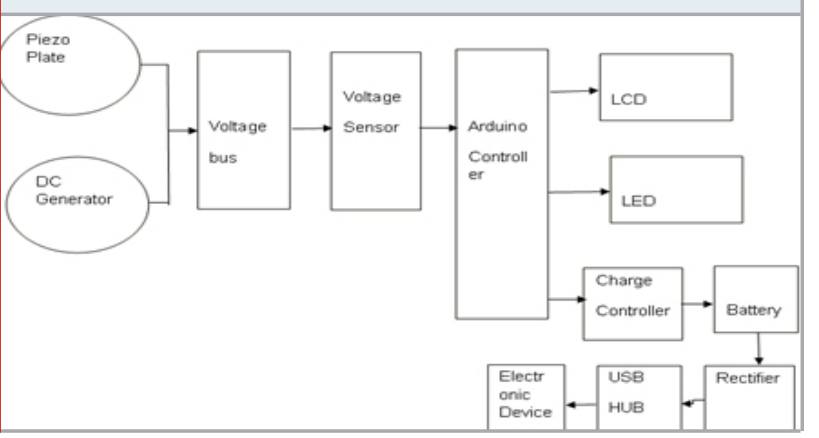

1.5.1. Piezo Sensor: This day the vast majority of the exploration inside the energy field is to create wellsprings of energy for the future. The time has come to discover sustainable surceases of energy for what's to come. Piezoelectric materials are large increasingly more concentrated as they end up being irregular materials with quite certain and intriguing properties. Truth be told, their materials can deliver electrical energy from mechanical energy for instance they can change over mechanical conduct like vibrations into power.

Such gadgets are usually referenced as vitality collectors and might be utilized in applications where outside force is inaccessible furthermore; batteries are not an achievable alternative. While later tests have demonstrated that these materials may be utilized as force generators, the amount of energy delivered is still low, thus the need to improve them. Piezoelectric materials have two properties that are characterized as immediate and banter impact. The direct impact is the property of certain materials to create electric charges on their surface when mechanical pressure is applied on them, while banter impact is that the property of certain materials to create mechanical pressure when an electrical charge is initiated.

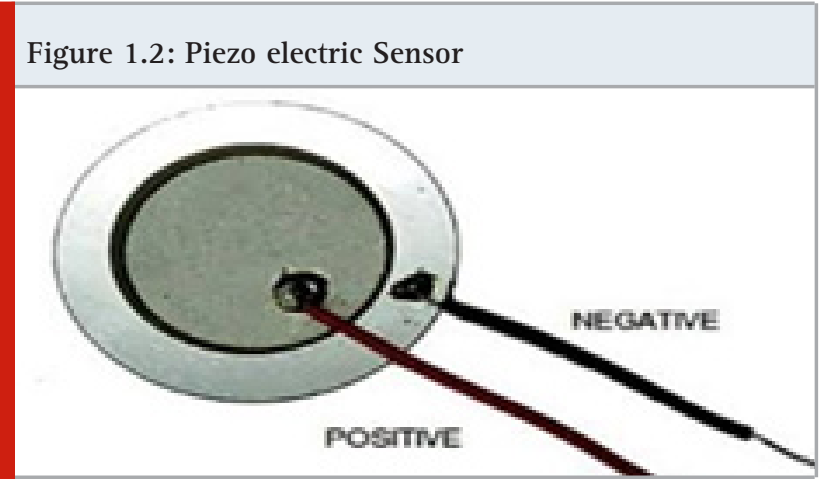

1.5.2. DC Generator: The conversion of electricity into energy is done by the electrical DC motors which act as actuators. The rotation of angles is used in the DC motor which is used in many different applications like rotation of pumps, fans, etc. Many different types of conventional electrical motors are considered. They are AC motor, DC motor and Stepper motors.

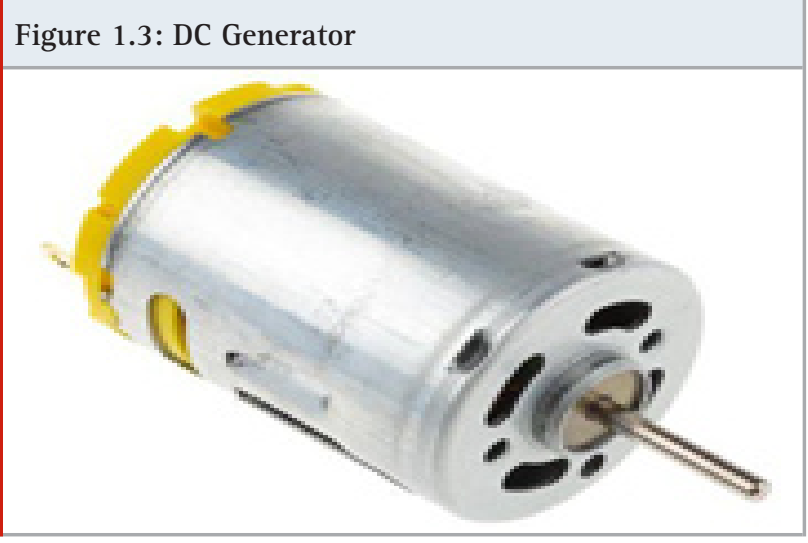

1.5.3. Voltage Sensor: The figure shows the sensor block of the voltage system which measures the voltages present at different points which has been converted into corresponding voltages for maximum and minimum value. The measured result is given by the sensor physical signal port.

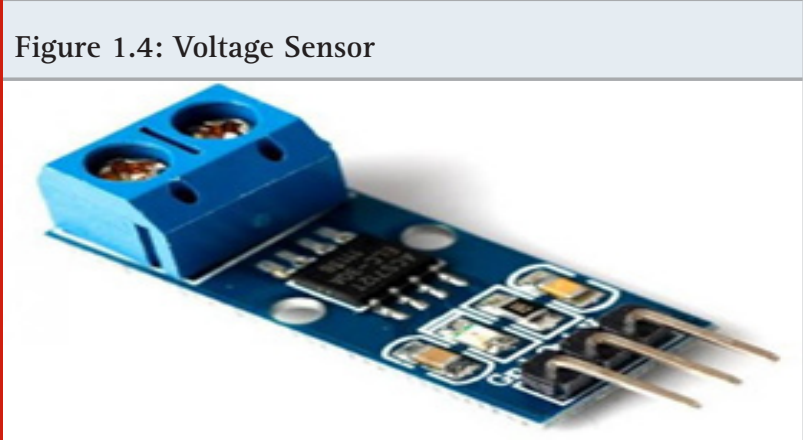

1.5.4. Charge Controller: A managed power supply is amazingly a lot of basic unit for many electronics products of this conductor in which there is an immovable system 
is present. The system will be damaged whenever there is a fluctuation in the voltage. The Air conditioner power supply gets changed over into consistent DC by this circuit. With the help of a transformer DC, an unregulated yield will be fixed to a proceeding with voltage. The circuit is framed from direct transformer 7805 close by capacitors and resistors with connect rectifier made up of diodes. From giving a perpetual voltage supply to assembling certain that yield arrives at continuous to the apparatus, the diodes which is present near the capacitors through which productive sign passed on.

Figure 1.5: Charge Controller

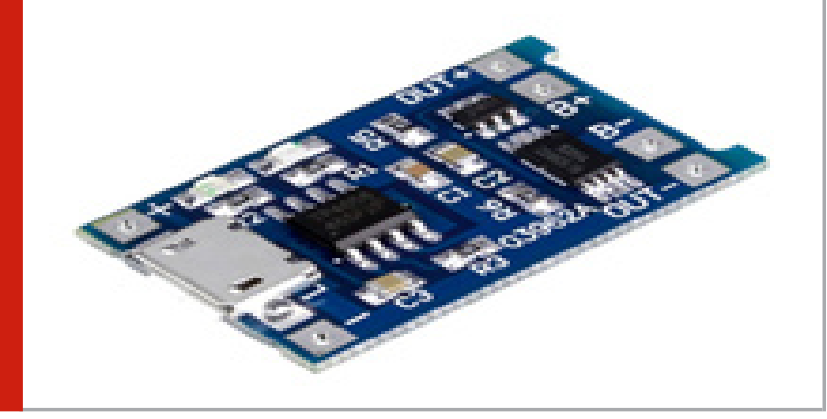

1.5.5. Rectifier: The conversion of alternating current into direct current is known as rectifier. Rectifiers have numerous utilization, however, they are frequently discovered filling in as segments of DC power supplies and high-voltage direct flow power transmission frameworks. Correction may serve in jobs other than to create a direct current for use as a wellspring of intensity.

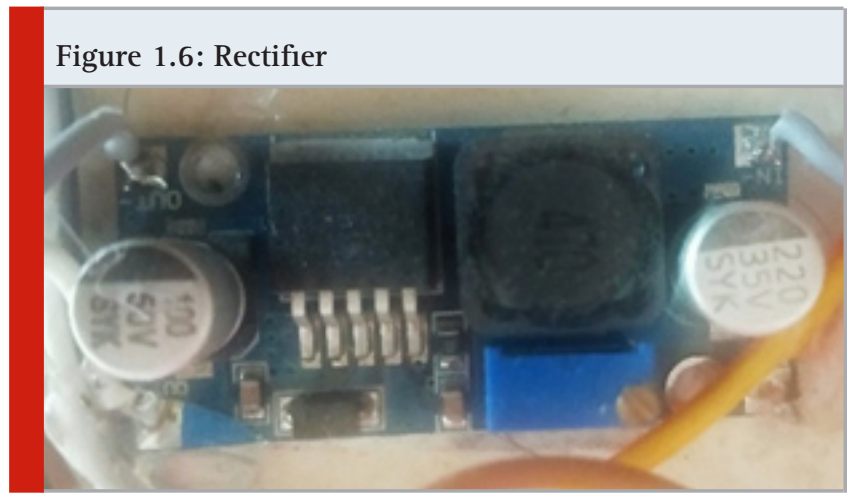

1.5.6. Rechargeable Battery: A small circuit is used for charging an electrical battery which is otherwise known as a rechargeable battery. It can also be otherwise known as storage battery or cell which is a secondary one. whenever there is no alternating current then battery is very helpfull. A circuit is used to generate the charge with the help of battery. Direct Current is stored in battery. Different voltaic cells are present in the battery. It consists of elctrolytes which is comprised of positive ions and negative ions.

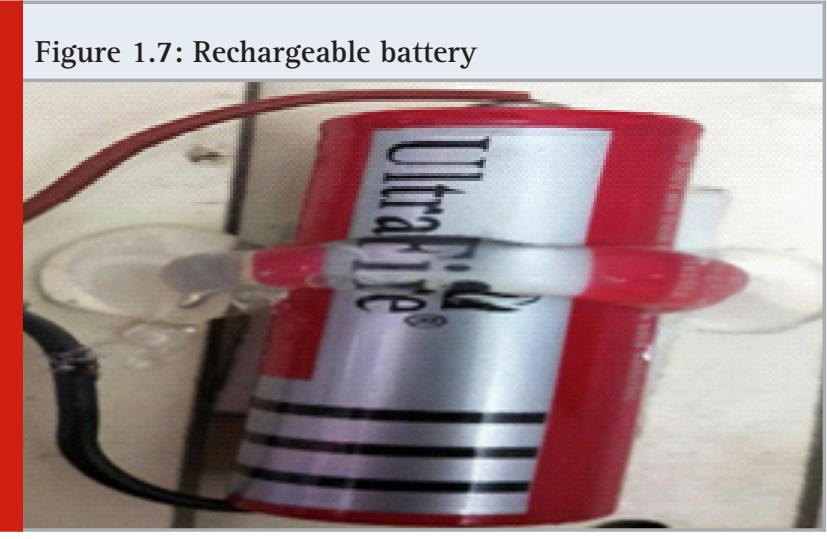

1.5.7. USB Hub: USB port is a standard connection affiliation interface for PCs and shopper's devices. USB speaks to universal series bus, an industry standard for short-division propelled data trades. USB ports license USB gadgets to be related with each other with and move propelled data over USB joins. They can similarly supply electric power over the connection to devices that need it.

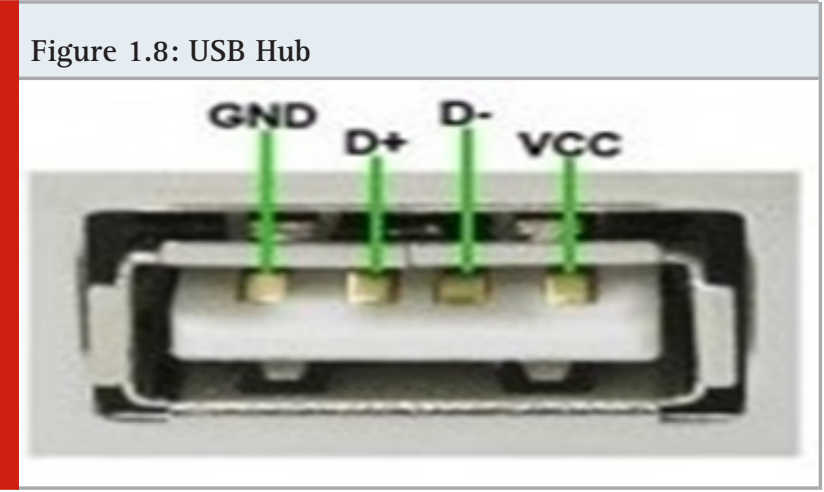

\section{RESULTS AND DISCUSSION}

If we install this model in crowded areas or energy farms, then the expected power output may be as below Let Mass of pedestrian $=65 \mathrm{~kg}$,

Distance travelled by plate $=10 \mathrm{~cm}$.

So Work done on the arrangement by impact

= weight of body* distance

$=65^{*} 9.81^{*} 0.1 \mathrm{Nm}$

$=63.765 \mathrm{~J}$

So Power output= work done/sec

$=63.765 / 60$ Watts

$=1.06275$ Watts.

It is like this power is only through Piezo. More power can be obtained by the combination of Piezo and DC generator that can be up to $5 \mathrm{~V}$ for each step. This can be stored in a battery. We can use the charged battery for mobile charging, street lights etc.

The aim is to save human energy which has to be converted into electrical energy. Now a day's number 
of people living in the country has been more so that it leads to more amount of power requirement daily which also paves the way for wasting the energy. So energy conservation is very important aspect in our day to day life. Hence voltage has been generated using the force exerted by the footstep. So it is very useful in all public places where there are more people gathering in a same place. It has been very useful if this system is placed in the entrance and the exit place in the public places. Thus the system is used for generating the voltage whenever people is walking or moving in a place. The various measurements are $\mathrm{u}=$ performed using a piezoelectric sensor.

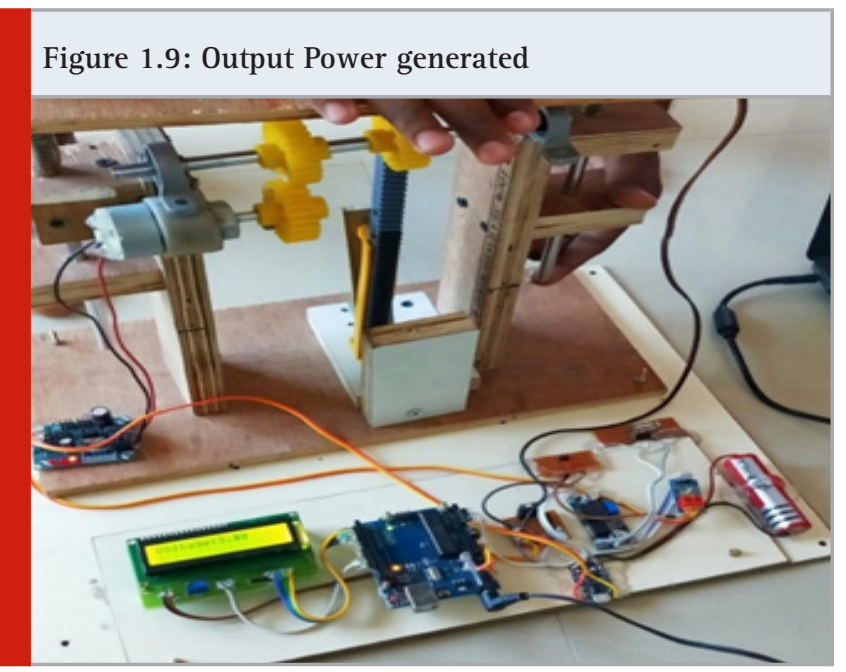

CONCLUSION

This paper examines the significance of the energy squandered and changed over it to a sustainable power source. It essentially manages the voltage created by the force applied through the piezo transducer and dc generator. Demands of power are expanding step by step and its utilization has gotten so progressed and relevant in the present lifesaver of an individual. This strategy produces power with the assistance of piezoelectric components and dc generators that utilize the energy of human strides. The capacitor utilized in the circuit stores the charge for future applications. To expand the effectiveness of the entire framework if super capacitors are utilized instead of the ordinary ones, at that point more charge can be put away than the traditional ones. The super capacitors store and release vitality without devouring a lot of vitality. Hence, the necessity of a steady increment of intensity cans be met by introducing these frameworks in vigorously pressed spots. This will be without a doubt conquer the energy emergencies as well as develop a healthy environment.

\section{REFERENCES}

Adhithan A., Vignesh K., and Manikandan M.: Method of Foot Step Power Generation Using Piezoelectric Sensor. International Advanced Research Journal in Science, Engineering and Technology, vol. 2, pp. 114 -123, (2015).
Afzal S., and Hafeez F.: Power Generation Footstep. International Journal of Advancements in Research \&t Technology, vol. 3, pp.219-248, (2014).

Ali A.J., and Ramesh G.P.: Analysis of Open, Closed Loop PI, PID, FLC and ANN Controllable Wind Energy System Using \-ZSI with PMSM. Lecture Notes in Electrical Engineering, vol. 601. Springer, Singapore, (2020).

Amit G.J.: Electrical Power Generation using Footstep. International Journal of Advancements in Research \& Technology, vol. 3, pp.141-178, (2017).

Bhoi A. K., Mallick P. K., Liu C. M., \&t Balas V. E.: Bioinspired Neurocomputing, Springer Nature, (2021).

Brata S., and Shekhar S.: Generation of Electricity Using Footstep. IJESRT, vol. 4, pp.698-724, (2018).

Dhanalakshmi G., Manjulai T., Mirunalini M., and Sangeetha T.M.: Footstep Power Generation System. International Journal of Engineering and Computer Science, pp. 261-298, (2016).

Fiebach J.B., Schellinger P.D., Jansen O., Meyer M., Wilde P., Bender J., and Hähnel S.: CT and diffusionweighted MR imaging in randomized order, Stroke, vol. 33, pp. 2206-2210, (2002).

Julie B., and Angelos S.: Footstep Power Generation. IJRASET, vol. 4, pp. 488-519, (2016).

Kumar C.N., Gowtham K., Mirunalini M., and Sangeetha M.S.: Power generation in automobile suspension. International Journal of Engineering and Computer Science, vol. 6, pp.468-501, (2018).

Kumar, H. and Ramesh, G.P., 2019. Reducing power feasting and extend network life time of IoT devices through localization. IJAST, 28, pp.297-305.

Magesh P., and Ramesh G.P.: Fuzzy logic control implementation of ultra-sparse matrix converter for renewable energy applications. 2017 International Conference on Information Communication and Embedded Systems (ICICES), Chennai, pp. 1-3, doi: 10.1109/ICICES.2017.8070782, (2017).

Mallick P. K., Balas V. E., Bhoi A. K., and Chae G.-S. (Eds.): Cognitive Informatics and Soft Computing: Proceeding of CISC 2019, Vol. 768, (2020).

Mallick P. K., Balas V. E., Bhoi A. K., and Zobaa A. F. (Eds.): Cognitive Informatics and Soft Computing: Proceeding of CISC 2017, Vol. 768, (2019).

Mishra S., Tripathy H. K., Mallick P. K., Bhoi A. K., and Barsocchi P.: EAGA-MLP-An Enhanced and Adaptive Hybrid Classification Model for Diabetes Diagnosis. Sensors, vol. 20, pp. 4036 (2020).

Mohanty M., and Panda H.: Power Extraction Using Piezo. J. Electroceram, vol. 1, pp. 103-145, (2017).

Nayan H., and Mathews S.: Power Generation Using Piezoelectric Material. American International University, May-2016, Dhaka, Bangladesh, pp. 314-341, (2016).

Nitashree M., Arati S., and Sayali G.: Foot Step Power Generation Using Piezoelectric Material. International Journal of Advanced Research in Electronics and Communication Engineering (IJARECE), pp.281-322, (2018).

Sherin M., and Ramesh R.R.: Power Generation from Footsteps. American International University, Dhaka, Bangladesh, pp. 381-420, (2017). 